\title{
Prevalence of Gingival Recession and its Relationship to Past Orthodontic Treatment in Nepalese Young Adults
}

\author{
Dr Bhageshwar Dhami,, Dr Priti Shrestha, ${ }^{2}$ Dr Sujaya Gupta, ${ }^{3}$ Dr Sujita Shrestha, ${ }^{4}$ Dr Rabindra Man Shrestha \\ 'Asst Prof, 3 Lecturer, Dept of Periodontics, 4Lecturer, Dept of Community \& Public Health Dentistry, \\ ${ }^{5}$ Asso Prof, Dept of Orthodontics, Kantipur Dental College, Kathmandu, Nepal \\ 2Lecturer, Dept of Periodontics, KIST Medical College, Lalitpur, Nepal
}

Correspondence: Dr Bhageshwar Dhami; Email: dhamibhagesh@hotmail.com

\section{ABSTRACT}

Introduction: Gingival recession is characterized by apical migration of gingival margin from the cementoenamel junction. Prevalence varies from 3-100\%, and appears to be lower in younger age groups.

Objective: To determine the prevalence and severity of gingival recession in young adult Nepalese population and to assess the relationship between brushing technique, smoking habit and past orthodontic treatment with gingival recession.

Materials \& Method: A cross-sectional study was carried out among 160 healthy patients (age 18-25 years) with routine dental examinations and information regarding age, smoking habit, oral hygiene habits, brushing technique and past orthodontic treatment. Clinical examination included visible gingival inflammation, visible dental plaque, and gingival recession. SPSS version 20 was used to analyze the data. Chi-Square test was used to evaluate relationships between the variables.

Result: Out of total participants; gingival recession was found in $21.3 \%$, gingivitis in $40 \%$ and plaque in $20 \%$. The prevalence, extent, and severity of recession were correlated with past orthodontic treatment. There was association between gingivitis, past orthodontic treatment and smoking with gingival recession.

Conclusion: Orthodontic patients must undergo regular oral hygiene performance and periodontal maintenance in order to maintain healthy gingival tissue during active orthodontic therapy. The combined orthodontic-periodontic interdisciplinary approach could be effective in these situations.

Key words: gingivitis, past orthodontic treatment, smoking, recession

\section{INTRODUCTION}

Gingival recession is characterized by apical migration of gingival margin from the cementoenamel junction. It can be localized or generalized and associated with at least one tooth surface.' Gingival recession usually leads to aesthetic problem and fear of tooth loss due to progressing destruction; it may also be associated with dentine hypersensitivity and/or root caries, and cervical wear. ${ }^{2}$

Several factors may play role in the development of gingival recession but not necessarily simultaneously or equally.' The etiology of gingival recession are calculus, because of inadequate access to prophylactic dental care, ${ }^{3}$ use of hard tooth brush, ${ }^{4}$ high frenal attachment, ${ }^{5}$ position of the tooth in the arch, ${ }^{6}$ tooth movement by orthodontic force e.g. excessive proclination of incisors, ${ }^{7}$ improperly designed partial dentures, ${ }^{8}$ smoking, ${ }^{9}$ subgingival restorations (increasing plaque accumulation) ${ }^{10}$ and chemicals e.g. topical cocaine application. ${ }^{11}$

The data suggests that gingival recession is universal and is a common manifestation in most populations. However, representative information is limited regarding the occurrence and risk factors of gingival recession. ${ }^{12}$

Prevalence varies from 3-100\% depending on the population and the methods of analysis; ${ }^{13}$ which appears to be lower in younger age groups. It is estimated that more than half of the adults in the United States have gingival recession; and it affects about one fourth of the dentition.

Epidemiological studies have investigated the role of fore-mentioned factors in the development of gingival recession in young adults in several countries; however only a limited number of studies have been conducted in Nepal; therefore it is important to collect relevant 
Table 1: Distribution of gingival recession according to FDI tooth number

\begin{tabular}{|l|l|l|l|l|l|l|l|l|l|l|l|l|l|l|}
\hline Tooth Number (Maxillary Teeth) & 17 & 16 & 15 & 14 & 13 & 12 & 11 & 21 & 22 & 23 & 24 & 25 & 26 & 27 \\
\hline Number of teeth with gingival recession & 1 & 5 & 0 & 5 & 0 & 0 & 1 & 2 & 0 & 2 & 3 & 0 & 2 & 0 \\
\hline Tooth Number (Mandibular Teeth) & 47 & 46 & 45 & 44 & 43 & 42 & 41 & 31 & 32 & 33 & 34 & 35 & 36 & 37 \\
\hline Number of teeth with gingival recession & 0 & 4 & 3 & 8 & 0 & 1 & 5 & 10 & 4 & 0 & 8 & 4 & 3 & 0 \\
\hline
\end{tabular}

information to assess the epidemiology, identification of the etiological factors and to establish preventive measures.

The objectives of the study were to determine the prevalence of gingival recession in a young adult Nepalese population and to assess the relationship between brushing technique, smoking habit and past orthodontic treatment with gingival recession.

\section{MATERIALS AND METHOD}

A cross-sectional study was carried among 160 healthy patients aged 18-25 years with routine dental examinations at the Department of Periodontics, Kantipur Dental College and Hospital from March to May 2016. The study was conducted after receiving permission from Institutional Review Committee. The participants were evaluated by a single examiner to avoid inter-examiner variation. The sample included 47 male $(29.4 \%)$ and 113 (70.6\%) female patients.

All fully erupted permanent teeth were examined on the facial aspect. Only the vertical extent of gingival recession was examined. Third molars and root stumps were excluded from the study. The examiner explained the aim of the study to the patients who agreed to sign the informed consent before clinical examination and to fill up a written questionnaire. The questionnaire consisted of information regarding age, smoking habits (number of cigarettes per day and years of smoking), oral hygiene habits, brushing technique and past orthodontic treatment.

Clinical examination included visible gingival inflammation, visible dental plaque, and gingival recession on the midfacial aspect of all teeth excluding the third molars. Gingival recession was measured as the distance from the cementoenamel junction to the free gingival margin by using William's periodontal probe up to the nearest millimeter. The prevalence, extent, and severity of gingival recession were associated with past orthodontic treatment.

All recorded data were statistically analyzed using SPSS version 20. Chi-square test was used to evaluate the association between the variables. The level of significance was set at $p<0.05$.

\section{RESULT}

According to the present study; gingival recession was found in $21.3 \%$ out of total participants and $0.02 \%$ among all examined teeth. The most common tooth with gingival recession was lower left central incisor followed by lower right and left premolars and upper premolars (Table 1). Gingivitis was found in $40 \%$ and dental plaque in $20 \%$ of the total participants.

Out of total participants; $37.5 \%$ had undergone orthodontic treatment in the past. Among them, $26.7 \%$ showed gingival recession compared with $18 \%$ with no past orthodontic treatment history; which was however not statistically significant (Table 2).

An association was found between severity and extent of recession to past orthodontic treatment. Only $1 \%$ patients with no past orthodontic treatment showed gingival recession of $3 \mathrm{~mm} .36 .7 \%$ with past orthodontic treatment showed recession of $1-2 \mathrm{~mm}$ compared to $17 \%$ with no orthodontic treatment. $(p=0.219)$. Similarly, $3.3 \%$ patients with past orthodontic treatment had three or more teeth with gingival recession compared to $5 \%$ with no past orthodontic treatment. $23.4 \%$ patients with past orthodontic treatment showed 1-2 teeth with gingival recession compared to only $13 \%$ with no orthodontic treatment $(p=0.237)$ (Table 3).

Table 2: Occurrence of gingival recession in relation to orthodontic treatment

\begin{tabular}{|c|c|c|c|c|}
\hline \multirow{2}{*}{ Gingival Recession } & \multicolumn{2}{|c|}{ Past Orthodontic Treatment } & \multirow{2}{*}{ Total (\%) } & p-value \\
\cline { 2 - 5 } & No (\%) & Yes (\%) & & 0.195 \\
\hline Absent & $82(82 \%)$ & $44(73.3 \%)$ & $126(78.7 \%)$ & (NS) \\
\hline Present & $18(18 \%)$ & $16(26.7 \%)$ & $34(21.3 \%)$ & $160(100 \%)$ \\
\hline \multicolumn{2}{|c|}{ Total } & $100(62.5 \%)$ & $60(37.5 \%)$ & \\
\hline
\end{tabular}


Table 3: Severity and extent of gingival recession in relation to orthodontic treatment

\begin{tabular}{|c|c|c|c|c|c|}
\hline & & \multicolumn{2}{|c|}{ Orthodontic Treatment } & \multirow{2}{*}{ Total (\%) } & \multirow{2}{*}{$p$-value $\wedge$} \\
\hline & & No (\%) & Yes (\%) & & \\
\hline \multirow{3}{*}{ Gingival Recession (in mm) } & 0 & $82(82 \%)$ & $44(73.3 \%)$ & $126(78.7 \%)$ & 0.219 \\
\hline & $1-2$ & $17(17 \%)$ & $16(36.7 \%)$ & $33(20.7))$ & (NS) \\
\hline & $3+$ & $1(1 \%)$ & $0(0 \%)$ & $1(0.6 \%)$ & \\
\hline \multicolumn{2}{|c|}{ Total } & $100(62.5 \%)$ & $60(37.5 \%)$ & $160(100 \%)$ & \\
\hline \multirow{3}{*}{ Extent (Number of teeth) } & 0 & $82(82 \%)$ & $44(73.3 \%)$ & $126(78.7 \%)$ & 0.237 \\
\hline & $1-2$ & $13(13 \%)$ & $14(23.4 \%)$ & $27(16.9 \%)$ & (NS) \\
\hline & $3+$ & $5(5 \%)$ & $2(3.3 \%)$ & $7(4.4 \%)$ & \\
\hline \multicolumn{2}{|c|}{ Total } & $100(62.5 \%)$ & $60(37.5 \%)$ & 160 (100\%) & \\
\hline
\end{tabular}

$\wedge$ Fisher exact test

The present study found that, prevalence of gingival recession was associated with smoking. Out of 160 participants; 10 (6.3\%) were smokers. Gingival recession were more in smokers, i.e. $70 \%$, as compared to nonsmokers $18 \%$, which was statistically significant $(p=0.014)$ (Table 4).

Similarly, $23.4 \%$ of patients with gingivitis had gingival recession compared to $19.8 \%$ with healthy gingiva which was not statistically significant. ( $p=0.581)$ (Table 5). There was no statistically significant association observed between gingival recession and brushing technique.

\section{DISCUSSION}

In this study, gingival recession was found in $21.3 \%$ of the total participants and $0.02 \%$ of all examined teeth. Similar results were found where prevalence of gingival recession ranged from $22.5 \%{ }^{14}$ to $27.7 \%{ }^{15}$ however other studies showed prevalence of gingival recession ranged above $50.0 \%$. $16,17,18$

The role of dental plaque accumulation and gingival inflammation in the development of gingival recession has been analyzed in previous epidemiological studies in which gingival inflammation was the most frequent precipitating etiological factor of gingival recession. ${ }^{18,19}$ In this study; $23.4 \%$ of subjects with gingivitis had gingival recession compared to $19.8 \%$ with healthy gingiva. Toker and Ozdemir ${ }^{20}$ recorded a positive association between gingivitis and occurrence of gingival recession, however these finding was not confirmed by other similar studies. ${ }^{18,21}$ The different results suggest the role of dental plaque and gingivitis as a risk factor for gingival recession.

Mostly young patients are referred for orthodontic treatment and they often suffer from plaque related gingivitis. ${ }^{22}$ Adolescents have certainly been shown to suffer worse gingivitis than adults during orthodontic treatment. ${ }^{23}$ It is well known that the presence of molar bands, brackets,

Table 4: Relationship of gingival recession with smoking

\begin{tabular}{|l|c|c|c|c|}
\hline \multirow{2}{*}{ Smoking } & \multicolumn{3}{|c|}{ Gingival Recession } & \multirow{2}{*}{ p-value^ } \\
\cline { 2 - 5 } & Absent (\%) & Present (\%) & Total (\%) & \\
\hline No & $123(82 \%)$ & $27(18 \%)$ & $150(93.7 \%)$ & \\
\hline Yes & $3(30 \%)$ & $7(70 \%)$ & $10(6.3 \%)$ & $0.014^{*}$ \\
\hline Total & $126(78.7 \%)$ & $34(21.3 \%)$ & $160(100 \%)$ & \\
\hline
\end{tabular}

$\wedge$ Fisher exact test, *statistically significant at $p<0.05$

Table 5: Relationship of gingival recession with gingivitis

\begin{tabular}{|l|c|c|c|c|}
\hline \multirow{2}{*}{} & \multicolumn{3}{|c|}{ Gingival Recession } & \multirow{2}{*}{ p-value^ } \\
\cline { 2 - 5 } & Absent (\%) & Present (\%) & Total (\%) & 0.581 \\
\hline Healthy gingiva & $77(80.2 \%)$ & $19(19.8 \%)$ & $96(60 \%)$ & (NS) \\
\hline Gingivitis & $49(76.6 \%)$ & $15(23.4 \%)$ & $64(40 \%)$ & $160(100 \%)$ \\
\hline
\end{tabular}


wires and other orthodontic auxiliaries expose the patient's teeth highly susceptibility to plaque accumulation. Almost every fixed orthodontic patient develops gingival disease at some time during the treatment. ${ }^{24}$ Gingival recession has been shown to be a common adverse factor during and/ or after the orthodontic treatment. Thin, delicate tissue is far more prone to exhibit recession during orthodontic treatment than the normal or thick tissue. If a minimal zone of attached gingiva or thin tissue exists, a free gingival graft enhances the tissue around the tooth which helps to control inflammation. This should be done before any orthodontic movement is begun. ${ }^{25,26}$ Recession has been noted more frequently while using buccal orthodontic movements. If the teeth with thin tissue are to be moved lingually, there is a potential for the tissue to move coronally and become thicker.

Tobacco smoking was associated with the occurrence of gingival recession in the present study. Past studies showed that tobacco smoking was regarded as one of the main risk factors for development of destructive forms of periodontal disease. 18,19,21 It was suggested that the combination of smoking and supragingival calculus was associated with localized and generalized gingival recession, and smoking may be a risk factor for gingival recession in adults with minimal periodontal destruction. ${ }^{27}$ However, it was not supported by a study done by Muller et $a^{28}$ and explained that the smoking status was not identified as a risk factor for the development of gingival recession. ${ }^{29}$

In the present study, the prevalence of gingival recession was associated with past orthodontic treatment. There was a relationship between the prevalence, severity and extent of recession to past orthodontic treatment. Orthodontic tooth movement outside the labial or lingual alveolar plate can lead to dehiscence and gingival recession. ${ }^{30}$ However, there was no relationship found between orthodontic movement in various age groups and gingival recession. ${ }^{30,31}$ In this study, most common tooth with gingival recession was lower left central incisor. It has been shown that most cases of gingival recession which occur during an orthodontic treatment located in the regions of upper and lower anterior teeth. ${ }^{32,33}$ In this study, gingival recession in past orthodontic patient are more in between 1-2mm and in 1-2 teeth, which could be because of gingival biotype, dental plaque and inflammation around those teeth or there was occurrence of gingival recession even before starting the orthodontic treatment.

Gingival recession is a common condition and can be seen in young adults which progresses over the time and if not treated may result in tooth mobility and finally tooth loss. Orthodontists should be aware of the etiology, prevalence, and associated factors of gingival recession, as well as treatment options, so that the appropriate treatment modalities can be offered to patients. The etiologic agents should be identified and removed as early as possible in order to avoid worsening of the clinical condition. Proper use of soft toothbrush and brushing technique should be advised to the patient. Various modalities of treating gingival recession are gingival graft (free gingival or connective tissue graft), guided tissue regeneration, restorations for the correction of sensitivity and orthodontic treatments.

\section{CONCLUSION}

Patients must undergo regular oral hygiene performance and periodontal maintenance in order to maintain healthy gingival tissue during active orthodontic therapy. The combined orthodontic-periodontic interdisciplinary approaches are more effective in these situations. Clinicians should schedule regular oral hygiene sessions for susceptible patients periodically during the entire duration of treatment. Pre-orthodontic assessment of the bone thickness and the thickness of overlying tissues should be performed to predict the likelihood of gingival recession post orthodontic therapy. Any periodontal therapy that enhance the gingival biotype should be done before any orthodontic movement is begun. It is always better to treat recession at the earlier stages. 


\section{REFERENCES}

1. Kassab MM, Cohen RE. The etiology and prevalence of gingival recession. J Am Dent Assoc. 2003; 134(2):220-5.

2. Dilsiz A, Aydin T. Gingival Recession Associated with Orthodontic Treatment and Root Coverage. J Clin Exp Dent. $2010 ; 2$ (1):30-3.

3. Van Palenstein Helderman WH, Lembariti BS, Van Der Weijden GA, van't Hof MA. Gingival recession and its association with calculus in subjects deprived of prophylactic dental care. J Clin Periodontol. 1998; 25(2):106-11.

4. Khocht A, Simon G, Person P, Denepitiya JL. Gingival recession in relation to history of hard toothbrush use. J Periodontol. 1993; 64(9):900-5.

5. Trott JR, Love B. An analysis of localized gingival recession in 766 Winnipeg High School students. Dent Pract Dent Rec. 1996; 16(6):209-13.

6. Zachrisson BU. Orthodontics and periodontics. In: Lindhe J, Berglundh T, Lang NP, editors. Clinical Periodontology and Implant Dentistry. 3rd ed. Copenhagen, Denmark. Munksgaard; 1997.

7. Artun J, Krogstad O. Periodontal status of mandibular incisors following excessive proclination. A study in adults with surgically treated mandibular prognathism. Am J Orthod Dentofac Orthop. 1987; 91 (3):225-32.

8. Wright PS, Hellyer PH. Gingival recession related to removable partial dentures in older patients. J Prosthet Dent. 1995; 74(6):602-7.

9. Gunsolley JC, Quinn SM, Tew J, Gooss CM, Brooks CN, Schenkein HA. The effect of smoking on individuals with minimal periodontal destruction. J Periodontol. 1998; 69(2):165-70.

10. Parma-Benfenati S, Fugazzato PA, Ruben MP. The effect of restorative margins on post-surgical development and nature of periodontium. Part I. Int J Periodontics Restorative Dent. 1985;5:31-51.

11. Quart AM, Butkus Small C, Klein RS. The cocaine connection. Users imperil their gingiva. J Am Dent Assoc. 1991; 122(1):85-7.

12. Slutzkey S, Levin L. Gingival recession in young adults: occurrence, severity, and relationship to past orthodontic treatment and oral piercing. Am J Orthod Dentofacial Orthop. 2008; 134:652-6.

13. Litonjua LA, Andreana S, Bush PJ, Cohen RE. Tooth brushing and gingival recession. Int Dent J. 2003; 53:67-72.

14. Albandar JM, Kingman A. Gingival recession, gingival bleeding and dental calculus in adults 30 year of age and older in the United States, 1988-1994. J Periodontol 1999; 70:30-43.

15. Marini MG, Greghi LA, Passanezi E, Santa'Ana ACP. Gingival recession: Prevalence, extension and severity in adults. J Appl Oral Sci. 2004; $12: 250-5$

16. Susin C, Haas AN, Oppermann RV, Haugejorden O, Albandar JM. Gingival recession: Epidemiology and risk indicators in a representative urban Brazilian population. J Periodontol. 2004; 75:1377-86.

17. Toker H, Ozdemir H. Gingival recession: epidemiology and risk indicators in a university dental hospital in Turkey. Intern J Dent Hyg. 2009; 7:115-20.

18. Chrysanthakopoulos NA. Prevalence and associated factors of gingival recession in Greek adults. J Inv Clin Dent. 2013 ; 4:1-8.

19. Sarfati A, Bourgeois D, Katsahian S, Mora F, Bouchard P. Risk assessment for buccal gingival recession defects in an adult population. J Periodontol 2010; 81:1419-25.

20. Toker H, Ozdemir H. Gingival recession: epidemiology and risk indicators in a university dental hospital in Turkey. Intern J Dent Hyg. 2009; 7:115-20.

21. Pires IL, Cota LO, Oliveira AC, Costa JE, Costa FO. Association between periodontal condition and use of tongue piercing: a case-control study. J Clin Periodontol. 2010; 37:712-8.

22. Derrick Willmot. Orthodontic treatment and the compromised periodontal patient. Eur J Dent. 2008; 2:1-2.

23. Hamp SE, Lundstrom F, Nyman S. Periodontal conditions in adolescents subjected to multiband orthodontic treatment with controlled oral hygiene. Eur J Orthod. 1982; 4(2):77-86.

24. Boyd RL, Baumrind S. Periodontal implications of orthodontic treatment in adults with reduced or normal periodontal tissue versus those of adolescents. Angle Orthod. 1992; 42:62: $117-26$

25. Foushee DG, Moriarty JD, Simpson DM. Effects of mandibular orthognathic treatment on mucogingival tissues. J Periodontol. 1985 56:727-33.

26. Maynard JG. The rationale for mucogingival therapy in the child and adolescent. Int J Periodontics Restorative Dent. 1987; 7:36-51.

27. Bergström J. Tobacco smoking and supragingival calculus. J Clin Periodontol. 1999; 26:541-7.

28. Müller HP, Stadermann S, Heinecke A. Gingival recession in smokers and non- smokers with minimal periodontal disease. J Clin Periodontol. 2002; 29:129-36.

29. Tomar SL, Asma S. Smoking attributable periodontitis in the U.S: findings from NHANES III. National Health and Nutrition Examination Survey. J Periodontol. 2000; 71:743-51

30. Allais D, Melsen B. Does labial movement of lower incisors influence the level of the gingival margin? A case-control study of adult orthodontic patients. Eur J Orthod. 2003; 25:343-52.

31. Melsen B, Allais D. Factors of importance for the development of dehiscences during labial movement of mandibular incisors: a retrospective study of adult orthodontic patients. Am J Orthod Dentofacial Orthop. 2005; 127:552-61.

32. Sadowsky C, BeGole EA. Long-term effects of orthodontic treatment on periodontal health. Am J Orthod. 1981; 80:156-72.

33. Polson AM, Reed BE. Long-term effect of orthodontic treatment on crestal alveolar bone levels. J Periodontol. 1984; 55:28-34. 